\title{
Alunas da Classe Trabalhadora: Sucesso Acadêmico e Discurso de Regulação
}

\author{
Luisa Saavedra \\ Universidade do Minho, Braga, Portugal
}

\begin{abstract}
Resumo
Este estudo, realizado em Portugal, analisa as entrevistas de 3 alunas da classe trabalhadora e as suas respectivas famílias. Estas alunas foram selecionadas a partir de um estudo anterior em que tinham sido investigadas as relações entre os resultados escolares e o seu meio sócio-econômico de origem. Este trabalho demonstrou que de cerca de 600 alunos provenientes de todos os meios sócio-econômicos, só 3 alunas da classe trabalhadora conseguiram obter classificações acadêmicas elevadas no $9^{\circ}$ ano, que é o final da escolaridade básica obrigatória. O objetivo do atual estudo é compreender como estas alunas obtiveram sucesso acadêmico e de que modos o avaliam. Os fundamentos teóricos e metodológicos foram os da "análise crítica do discurso" que permitiram considerar a possibilidade destas alunas terem obtido um rendimento escolar elevado pela interiorização do discurso da classe média sobre a escola, embora este pareça estar dissimulado, oculto ou mascarado tanto para as alunas como para as suas famílias.

Palavras-chave: Análise crítica do discurso; discurso de regulação; identidade; motivação para a realização escolar; sucesso escolar.
\end{abstract}

\section{Working-Class Female Students: Academic Success and Regulating Discourse}

\begin{abstract}
This study, conducted in Portugal, analysed interviews of 3 female students from working-class backgrounds and their respective families. These students were selected from a previous study in which academic results and their link to socio-economic background were analysed. That work demonstrated that, out of 600 students from all socio-economic backgrounds, there were only three working-class female students who achieved high academic results up to the 9-th and final year of compulsory education. The aim of the present study is to understand why these three female students have succeeded, and how they appreciate this success. "Critical discourse analysis" has been the theoretical and methodological basis for this work and has permitted to consider the possibility that these female students had achieved such great academic success by internalising the discourse of the middle classes, although this is dissimulated, hidden and masked forboth for the female students and their families.

Keywords: Critical discourse analysis; academic success; identity; motivation for academic achievement; regulating discourse.
\end{abstract}

A psicologia moderna tem como pilares básicos da sua estrutura três questões centrais: a ênfase na mente como entidade individual, um mundo/realidade a que é possível aceder de uma forma objetiva e a linguagem como veículo condutor da verdade. Talvez, devido à sua forte identificação com as ciências naturais a psicologia teve, ou tem tido, alguma dificuldade em ser permeável às teorias, metodologias e práticas que têm influenciado as ciências sociais que mais se lhe avizinham (Gergen, 2001). Progressivamente, contudo, o pós-modernismo e o pós-estruturalismo foram, também, invadindo o campo da psicologia (Fee, 2000; Gergen, 1994; Kvale, 1992; Nogueira, 2001; Parker, 1992). Sob a influência destas perspectivas, a linguagem adquiriu uma importância primordial na análise da realidade social levando Edwards e Potter (1992) a falarem numa "psicologia discursiva", para a qual os fenômenos psicológicos não são uma entidade intrínseca aos sujeitos, mas "existem" nos discursos, nos significados e nos posicionamentos que os indivíduos têm

\footnotetext{
${ }^{1}$ Endereço para correspondência: E-mail: luisasaavedra@sapo.pt
}

face aos vários recursos discursivos disponíveis nos contextos sócio-culturais em que se situam (Harré \& Gillet, 1994).

Este interesse crescente pelo papel e função da linguagem na construção social da experiência (Gergen, 1982, 1985), este "voltar-se para a linguagem" (Harré, 1995), refletiu-se no desenvolvimento da análise do discurso na psicologia que não é apenas um método, mas uma abordagem global sobre a vida social e a sua investigação (Potter, 1996).

$\mathrm{Na}$ análise do discurso a linguagem não é encarada como um meio de aceder a processos mentais internos, pois o próprio cérebro é discursivamente constituído sendo, antes, conceptualizada como uma prática social e como recursos que permitem aceder a essas práticas (Potter, 1996). Neste sentido, linguagem não é, por isso, uma "ferramenta" para descrição da realidade ou um meio de comunicação, mas uma prática social (Wood \& Kroeger, 2000).

A análise de discurso sendo uma nova abordagem ao estudo de temas da psicologia (Llombart, 1993; Parker, 1992; Potter \& Wetherell, 1987), aparece como alternativa aos métodos mais ortodoxos de investigação da vida social (Iñiguez \& Antaki, 1994; Wood \& Kroeger, 2000).

O estudo que se apresenta nas páginas seguintes é inspirado na "análise crítica do discurso", que concebe os 
discursos de uma forma distinta dos "repertórios interpretativos" (Potter, 1996; Potter \& Wetherell, 1987). Acentua a relação entre discurso e poder, no sentido em que Foucault (1994) relaciona poder com conhecimento, e o modo como as pessoas, ao lidarem com o poder e a sua sujeição a ele, emitem discursos de resistência. Procura nos textos as contradições entre diferentes significados, tentando identificar os que são dominantes e subordinados e salientando processos de resistência (Parker, 1999). Finalmente, apóia-se no pressuposto de que as nossas idéias são constituídas por padrões de discurso que fogem ao controle de cada um e que existe uma luta pelo significado que é levada a cabo sempre que as pessoas procuram contar uma história coerente sobre si próprias (Parker, 1999).

\section{Da Busca pela Coerência à Multiplicidade de Discursos e Identidades}

Nesta busca pela coerência, contudo, vários discursos podem competir entre si e criar uma visão diferente e até incompatível da realidade. Como é referido por diversos autores (Davis \& Harré, 1990; Deleuze \& Guattari, 1987; Goffman, 1993; Weedon, 1987), as pessoas constróem imagens sobre si próprias que nem sempre formam um todo coerente. $\mathrm{O}$ conceito de multiplicidade defendido, por exemplo, por Deleuze e Guattari (1987) implica a concepção de várias identidades que não têm um padrão fixo ou comum e que emergem através das diversas comunidades que habitamos e da multidimensionalidade em que participamos na vida social.

Além disso, é na relação que estabelecemos com os outros que vamos compreendendo e construindo a nossa experiência e identidade (Davis \& Harré, 1990), o que se torna bem explícito nas palavras de Bakhtin (1984, p. 287):

Tenho consciência de mim e torno-me eu apenas enquanto me revelo para o outro, através do outro e com a ajuda do outro ... Ser, significa comunicar ... ser, significa ser para o outro e, através dele, para si próprio.

De modo semelhante, Goffman (1993) refere que o self é instável e que resulta das interações do ator com a sua audiência. Ao atuar, o sujeito pretende mostrar um certo tipo de self que seja aceito pela audiência.

Estas últimas questões tornam-se tanto mais pertinentes quando se trata de analisar entrevistas, como é o caso deste trabalho, pois podemos sempre supor que muito do que é dito só o é na presença concreta do entrevistador(a) que ocupa uma determinada posição face ao(à) entrevistado(a). Isto significa que a experiência e a identidade das alunas, face o seu sucesso acadêmico, vai sendo edificada na interação entrevistadora/entrevistada e que se exprime através dos discursos disponíveis no contexto social e cultural a que pertencem (Davis \& Harré, 1990).

\section{Método}

Tendo por base os pressupostos acima referidos, buscouse analisar, recorrendo a entrevistas, os discursos de alunos e alunas que, simultaneamente, tivessem elevado sucesso acadêmico (considerado este unicamente por referência às classificações escolares) e pertencessem à classe trabalhadora. Estes dois critérios foram escolhidos por se considerar que estes alunos e alunas se encontrariam numa posição contraditória face à sua posição de classe social de origem, tendo em conta que a maioria dos estudantes da classe trabalhadora obtêm classificações escolares mais próximas do insucesso do que do sucesso acadêmico (Roberts, 1993; Saavedra, 2001a, 2001b).

Interessava, pois, determinar os vários significados que as alunas, e as suas respectivas famílias, atribuíam ao seu sucesso escolar e como se posicionavam face aos discursos disponíveis sobre as atribuições ao rendimento acadêmico, nomeadamente sobre a inteligência e o estudo.

\section{Participantes}

Este estudo foi realizado em Portugal e baseia-se em entrevistas realizadas com 3 alunas do $10^{\circ}$ ano de escolaridade e respectivos familiares. Os pais e mães das alunas eram operários exceto os pais da aluna $A$, que possuíam 6 anos de escolaridade e tinham como habilitações acadêmicas 4 anos de escolaridade.

As pessoas entrevistadas residiam na periferia da cidade do Porto, numa área com uma elevada percentagem de indústria e comércio. A escola é majoritariamente freqüentada por alunos e alunas provenientes da classe trabalhadora, ao nível da escolaridade obrigatória.

Estas alunas foram selecionadas a partir de um estudo anterior em que se analisaram as classificações escolares em função da classe social e do sexo. De uma amostra de cerca de 600 alunos, de todas as classes sociais, estas alunas foram as únicas da classe trabalhadora que conseguiram obter classificações escolares elevadas (níveis de 4 e 5 numa escala de 1 a 5) até ao final da escolaridade obrigatória de 9 anos. Salienta-se que não foram intencionalmente selecionados elementos do sexo feminino, mas que aconteceu terem sido unicamente as alunas a obterem as melhores classificações escolares.

\section{Instrumentos}

As entrevistas foram semi-estruturadas, realizadas individualmente com cada uma das alunas e seus familiares. 
Os dados resultam das respostas das alunas às seguintes questões: 1) passado escolar e perspectivas para o futuro ${ }^{2}$; 2) auto-percepções sobre as suas classificações escolares; 3) atribuições causais para o sucesso escolar (métodos de estudo, apoio de familiares, etc.). Os familiares pronunciaramse sobre as seguintes questões: 1) tipos de apoio prestado à aluna e como se concretizam; 2) hábitos de deslocação à escola e quais são os motivos dessas deslocações.

\section{Análise dos Dados}

A análise das entrevistas foi inspirada no método analítico do discurso de Parker (1992) que, em termos metodológicos recorre a meios essencialmente taxonômicos (em vez de se preocupar com pequenos segmentos de texto, como outros métodos de análise de discurso), procurando identificar e descrever quais são os principais discursos em questão. Relativamente a determinados tópicos procura-se saber quais os discursos disponíveis, como se desdobram e para que é que eles servem (Rogers, 1998). É enfatizada a natureza coletiva do discurso, atribuindo menos importância aquilo que o indivíduo diz em contextos particulares, e salientando o modo como o discurso lida com os recursos sociais e culturais que são usados nas atividades humanas (Parker, 1992,1999). Assim, mais importante do que as pessoas em si, são os textos ou discursos que essas pessoas produzem (Wood \& Kroeger, 2000). O discurso, tal como é usado na "análise crítica do discurso", diz respeito aos "padrões de significados que organizam os vários sistemas simbólicos, que os seres humanos habitam e que são necessários para fazermos sentido para os outros" (Parker, 1999, p. 3).

Concretizando, numa primeira fase as entrevistas foram cuidadosamente lidas para se formar uma idéia sobre os temas centrais abordados incluindo os inicialmente previstos na estrutura da entrevista e outros que tinham espontaneamente surgido. Depois de se ter determinado que os principais conteúdos circulavam em torno do seu sucesso e dos colegas, da relação com os professores e da participação dos encarregados de educação na vida acadêmica, os excertos que incluíam estes temas foram selecionados do total das entrevistas. Para cada tema, foram identificados padrões de discursos semelhantes e contrastantes, ambigüidades, contradições e ausências nos discursos. Esta última etapa levou à estruturação de vários discursos, aos quais foram atribuídos nomes/títulos, em

\footnotetext{
${ }^{2}$ Não é possível neste espaço referir toda a informação recolhida ao longo das entrevistas. Ressalta-se que as três entrevistadas possuem até o momento um percurso escolar de sucesso, desde o início da sua escolaridade, e que em termos de futuro todas pretendem ingressar no ensino superior.
}

função dos seus efeitos (objetivos e conseqüências do discurso). Finalmente, foram escolhidos os excertos que melhor ilustravam os discursos identificados. $\mathrm{O}$ desenrolar deste trabalho de análise mais do que linear foi constituído em espiral, pois um passo seguinte implicou, freqüentemente, um refazer do anterior.

\section{Resultados e Discussão}

Ao longo das várias entrevistas as alunas falaram tanto de si como do papel dos seus familiares na sua vida escolar e estes, tanto das alunas como de si próprios. Ambos fizeram ainda referência aos professores e à sua relação com eles.

Tendo em conta o modo como os discursos se estruturaram, através da análise efetuada, optou-se pela seguinte apresentação: 1- "discurso dos familiares sobre o sucesso das alunas"; 2- "discursos das alunas sobre o sucesso escolar"; 3 - "discurso sobre os professores".

\section{Discurso dos familiares para explicar o sucesso das alunas: $\mathbf{O}$ discurso da socialização}

Este discurso diz respeito aos recursos utilizados por pais, mãe e irmãos para explicar o sucesso das alunas. Inclui, também, as referências das alunas relativamente ao comportamento dos seus familiares para com elas, neste domínio.

As justificativas invocadas pela família, ou pelas alunas relativamente ao comportamento dos seus familiares para com elas, para explicar o sucesso escolar das educandas são variadas e freqüentemente espontâneas. Poder-se-ia, de uma forma genérica considerar que todas as explicações invocadas cabem dentro de um discurso que se poderia designar de "discurso da socialização", porque a idéia que guia todas as produções discursivas aqui inseridas é de que o discurso/ prática dos pais tem um peso considerável no sucesso escolar destas alunas, quer através da modelação ${ }^{3}$ (Bandura, 1986), quer através de estratégias de motivação para a realização escolar.

Este discurso foi organizado em duas construções discursivas distintas: 1) motivação para a realização escolar; e 2) a importância das figuras maternas. Apesar de na primeira construção discursiva se encontrarem também fatores que promovem modelação (a ida dos pais à escola, por exemplo, pode desenvolver nas alunas o sentido de responsabilidade que está manifesta nestas figuras), pretendeu-se acentuar que na segunda construção discursiva o papel da modelação através da figura materna, é mais evidente do que na primeira.

\footnotetext{
3 “modeling", em inglês.
} 


\section{A motivação para a realiz̧ação escolar}

A construção discursiva de motivação para a realização é uma parte importante do discurso da socialização. Ao longo das entrevistas, está patente um acentuado interesse pelo percurso acadêmico das alunas desde a escola primária:

Mãe da Aluna B - A (nome da aluna) foi sempre uma boa aluna, começou assim na primária, nunca repetiu, graças a Deus. Passou para a preparatória e continuou sempre a ser boa aluna. Acompanhei-a sempre, que eu agora estou em casa, mas trabalhei 21 anos na fábrica e, claro, quando era preciso faltar, ficasse o que ficasse, o que me interessava a mim era saber como a minha filha estava na escola, ou bem ou mal eu tinha de saber.

Esta preocupação com as educandas caracteriza-se por diversas práticas: deslocação dos familiares à instituição escolar (presente no discurso da mãe da aluna B e na aluna C), ajuda nos trabalhos de casa, encorajamento para os mesmos, crença na eficácia pessoal das alunas. Além disso, há desvalorização da aprendizagem de tarefas domésticas freqüentemente assumidas como fatores determinantes da construção e desenvolvimento da identidade feminina, ainda mais acentuada na classe trabalhadora (Bates, 1993; Perista, 1999), como é revelado pelo discurso da aluna C:

Aluna C - A minha mãe está sempre a dizer 'Tu em casa não precisas de fazer nada, precisas é de estudar ' ... Porque a minha mãe vai sempre às reuniões todas, nunca falta e quer sempre saber o que se passa.

A transmissão de expectativas elevadas relativamente ao seu futuro escolar é uma prática discursiva a que estes pais recorrem para implementar o sucesso das filhas, o que vai ao encontro a diversos trabalhos que têm salientado a importância do apoio emocional e de expectativas elevadas por parte do meio familiar e que são particularmente eficazes nos meios econômicos e sociais mais desfavorecidos (Bandura, 1991; Barr \& Parrett, 1995; Manning \& Baruth, 1995; Rak \& Patterson, 1996; Sagor, 1996; Schunk, 1990; Weiner, 1991). O fato da mãe "nunca faltar" a nenhuma reunião da escola "e querer sempre saber o que se passa" (como salienta a aluna C) ou da referência ao "acompanhei-a sempre ... quando era preciso faltar, ficasse o que ficasse" (da mãe da aluna B) parece ter como conseqüência uma "obrigação" por parte das filhas de responderem às expectativas da família, aspecto que se torna mais explícito através do excerto seguinte:

Mãe da aluna $C-\ldots$ eu não me sinto preparada para levar com um desgosto das minhas filhas, está a entender? ... É o que lhes digo sempre 'Façam sempre com que eu nunca seja chamada por uma professora, como muitos pais, que vêm de lá com as lágrimas pela cara abaixo, porque os filhos são uns trastes, porque fazem asneiras, porque não estudam, ... e eu acho que não estou preparada para isso ... Porque se a gente se sacrifica tanto para lhe dar uma boa estabilidade na vida, acho que nós não merecíamos que elas nos fizessem isso...

Se é verdade que a classe média investe, igualmente, de uma forma considerável em bens econômicos e emocionais para que os seus filhos e filhas obtenham sucesso acadêmico (Allatt, 1993), a principal diferença entre os filhos(as) da classe média e as famílias em foco neste estudo reside, essencialmente, nos recursos financeiros. Enquanto as primeiras dispõem de meios econômicos para escolher a escola que melhor formação pode fornecer aos seus educandos, as famílias entrevistadas têm que se sujeitar à instituição escolar que fica mais próxima da sua residência, investindo os seus poucos recursos financeiros na aquisição de bens culturais (Ex.: computadores e livros) que permitam às filhas não ficarem em situação de desvantagem face aos colegas cultural e economicamente mais favorecidos. Mas a satisfação destas necessidades culturais implica um esforço acrescido, que se caracteriza em horas-extra de trabalho, ausência de férias, etc. $\mathrm{O}$ investimento no trabalho é construído, simultaneamente, com orgulho e espírito de sacrifício e com o objetivo de garantir melhores condições econômicas para as filhas, como está patente nas duas transcrições seguintes da família C:

Mãe da Aluna C - ... Eu trabalhava 48 horas seguidas, quando não era mais, sem parar, claro, para conseguir dar aos filhos aquilo que eles hoje têm que não é muito, mas é muito mais do que aquilo que a gente tinha, ou que os nossos pais nos puderam ou quiseram dar.

Pai da Aluna C - há alguns pais que têm mais estudos e mesmo assim não se interessam muito ... eu e a minha mulher não saímos para lado nenhum, eu trabalhei e não tinha férias, nas férias ia trabalhar para ganhar mais dinheiro, trabalhava horas extras ... Tenho de trabalhar. Chego a ganhar mais horas extras de que o ordenado e é assim que eu me safo ...

No segundo excerto, o pai parece indicar que, para ele, não existe uma relação direta entre o interesse dos pais pela vida acadêmica dos filhos e a formação acadêmica dos progenitores -"bá alguns pais que têm mais estudos e mesmo assim não se interessam muito ...". No entanto, parece estabelecer uma relação geral entre interesse dos pais, o seu investimento no trabalho e o sucesso escolar dos filhos.

Em termos de conclusão poder-se-ia dizer que o principal efeito, ou conseqüência, do "discurso da motivação para a 
realização escolar" seria o de uma "moeda de troca": as alunas fazem o que lhe compete, estudando, e têm como retribuição da parte da família um interesse profundo pelas questões da vida acadêmica. Mas, simultaneamente, há um efeito de modelação/identificação do esforço dos pais no trabalho, que é reproduzido pelas alunas na própria atividade acadêmica.

\section{A importancia da figura materna}

A construção discursiva da "importância das figuras maternas" faz parte do discurso da socialização na medida em que há uma identificação com as figuras paternas que leva a que elas funcionem, para as filhas, como um modelo a interiorizar. Para além do grande envolvimento dos pais e mães no trabalho se constituir como modelo para o envolvimento das alunas no estudo, outro aspecto parece ter um impacto significativo na sua motivação acadêmica: é o desejo explícito das mães em terem prolongado os seus estudos.

Ao longo das entrevistas, as mães - e não os pais sublinharam o seu desejo de terem continuado os estudos (ao contrário da maior parte dos pais e mães da classe trabalhadora (Rak \& Patterson, 1996) o que deixa implícito que possuem uma imagem positiva da escola ou, pelo menos, dos benefícios que esta lhes poderia trazer.

Mãe da Aluna B - O meu marido é uma pessoa que quer que os filhos estudem, mas não presta muita atenção, será por ser da construção civil? ... mas, eu fiz sempre força para que os meus filhos estudassem ...

Mãe da Aluna B - ... porque eu nem a $4^{a}$ classe tenho, podiaa tirar em qualquer altura mas o meu marido tem um feitio muito esquisito, tem um feito difícil ... e eu gostava, sou franca, eu gostava de saber mais do que aquilo que eu sei, ainda há pouco o padre falou na missa e eu disse 'Eu vou-me matricular na escola da noite'.

$\mathrm{Na}$ mesma linha de idéias a aluna $\mathrm{C}$, enfatiza a diferente postura entre a mãe e o pai face ao estudo:

Aluna C -. O meu pai, por exemplo, não fala assim tanto comigo, mas a minha mãe está-me sempre a incentivar 'estuda, tens de estudar'.

Tendo em conta que estas alunas passaram mais tempo com as mães do que com os pais (pela própria referência das alunas ao longo das entrevistas, porque nenhuma freqüentou o jardim de infância e a mãe da aluna $C$ trabalhava em casa) e pela sua própria condição de sexo, pode-se supor que estes aspectos tenham facilitado, também a este nível, uma maior identificação com a figura materna. Este fato pode ter criado condições facilitadoras para que os desejos não concretizados das mães fossem projetados nas filhas e estas projeções funcionassem como um modelo provocando simultaneamente uma modelação de comportamento e uma motivação para a realização. Chamarei a esta produção discursiva uma "modelação projetada", porque as mães projetam nas filhas os seus desejos não realizados e estes funcionam como modelo para as alunas. Esta idéia é tanto mais reforçada pelas razões invocadas pelas mães para terem abandonado os estudos se centraram em fatores de ordem econômica e social e nunca sobre um desinvestimento na escola:

Mãe da Aluna C - em casa dos meus pais era assim: os rapazes tinham direito a tudo as raparigas não tinham direito a nada.... no meu tempo já havia moças que estudavam mas, o meu pai e a minha mãe tinham aquela idéia de dizer 'as raparigas não precisam de nada, porque elas quando casarem têm o marido que as sustentam', mas não é assim!... Uma mulher tem de trabalhar ao lado do marido senão não consegue fazer face à vida e mais agora,... Claro que esse desgosto fica sempre..."

Mãe da Aluna B - eu não fiz a $4^{\mathrm{a}}$ classe porque queimei-me e estive quase 4 anos escaldada ... Fiz a $3^{\text {a }}$ classe. Porque aí está, passei o meu tempo, a bem dizer, no hospital ... E depois claro, a vida era diferente, depois saí do hospital e os meus pais também não tinham grandes possibilidades, prontos...

Em qualquer dos casos perpassa a tristeza por este abandono precoce da escolaridade (Claro que esse desgosto fica sempre... e os meus pais também não tinham grandes possibilidades, prontos) e um acentuar das diferenças de estilo de vida entre o passado e o presente: uma mulher tem de trabalhar ao lado do marido senão não consegue fazer face à vida e mais agora e a vida era diferente.

Esta forte motivação das mães para a escolaridade, aliadas a uma identificação das filhas com estes desejos poderão ter sido um grande incentivo das alunas para o estudo para, através dele, poderem concretizar os sonhos maternos não realizados.

Uma vez mais o efeito discursivo passa pela estimulação para uma continuação de escolaridade a mais prolongada possível.

\section{Discursos usados pelas alunas para explicar o seu sucesso: A inteligência e o esforço}

Os discursos incluídos nesta seção são, predominantemente, utilizados pelas alunas para explicar o seu sucesso, embora haja algumas referências a discursos dos familiares sobre a atividade escolar das educandas.

Inquiridas com uma questão aberta e geral sobre qual considerariam ser a razão do seu sucesso escolar as alunas 
dividiram-se entre discursos centrados na inteligência e discursos centrados no esforço onde se manifestam versões ambíguas, contraditórias e conflituosas para a explicação do seu sucesso acadêmico.

A inteligência e o esforço parecem ser os discursos mais utilizados, quer pela psicologia escolar, quer pelo senso comum (Weiner, 1991). As alunas entrevistadas não recorreram, no entanto, espontaneamente a estes discursos para explicar o seu sucesso acadêmico.

Assim, face à questão se consideram-se inteligentes surgem freqüentes contradições.

Aluna A - Inteligente? O que é que se entende por inteligente? ... Inteligentes somos todos, temos é maior ou menor capacidade para aproveitar isso. Eu acho que é isso ... Tenho alguns colegas inteligentes, há é quem não aproveite isso...

A aluna A considera-se inteligente para logo desvalorizar esse fato ao afirmar que somos todos inteligentes. A segunda contradição acontece quando, depois de ter dito que somos todos inteligentes, considera que na sua turma há alguns alunos inteligentes o que o é o mesmo que admitir que nem todos o são.

Aluna B - Não sei, acho que não sou inteligente, mas sei lá, estudo e tento conseguir os objectivos mínimos ... mas às vezes também noto que é a pouca vontade que eles (colegas) têm de aprender ...

Em contrapartida, a aluna B valoriza os estudo e os objetivos que se propõe alcançar (que claramente não são mínimos, pois as suas classificações escolares são elevadas e pretende ingressar no ensino superior) em detrimento da sua capacidade intelectual, considerando que se os seus colegas só não têm boas notas porque não querem aprender.

Aluna C - Não, acho que não, porque considerar-me inteligente era considerar que tinha boa cabeça e que pensava bem. Por exemplo, agora não estudo tanto e se fosse inteligente estudava mais, porque acho que tinha capacidade para melhor. Se fosse verdadeiramente inteligente esforçavame mais...

A aluna $\mathrm{C}$ ao negar a sua inteligência refere que se fosse inteligente estudaria mais, mas ao reconhecer que teria capacidade para tirar melhores notas, acaba por admitir a sua capacidade intelectual. Ao mesmo tempo acentua a idéia de que fazer esforço é sinal de inteligência.

As múltiplas contradições face ao conceito de inteligência manifestam-se ainda entre o não reconhecimento de serem inteligentes e a posterior afirmação das suas preferências por disciplinas que fazem, sobretudo, apelo ao raciocínio:
Aluna C - Por exemplo, matemática acho que não é de decorar é mesmo de perceber, se uma pessoas decorar não percebe nada. Até ao $9^{\circ}$ ano foi sempre a disciplina que eu mais gostei.

Aluna B - Gosto mais de matemática e físico-química. Adoro química. Porque são disciplinas que não se tem de decorar, mas sim perceber...

No que diz respeito ao investimento no estudo encontram-se, também, algumas ambigüidades/incoerências, já que todas foram unânimes em afirmar que não the dedicavam muito tempo. Contudo, ao abordarem outros temas acaba por se compreender que as primeiras afirmações não eram tão lineares como foram apresentadas:

Aluna C - Acho que devia estudar mais. Tenho de admitir isso. Tiro apontamentos quando os professores estão a falar e vejo o que é mais importante. Depois, é só chegar a casa e desenvolver um bocado e passar para uma folha. Por exemplo, para estudar para os testes eu vejo a matéria toda e faço resumos de tudo. No dia em que vou ter o teste, nos intervalos vou lendo para aquilo ficar mais fresco ... Enquanto, por exemplo, os meus colegas estão a divertir-se e eu penso que também queria estar, mas não, estou a ler aquilo para memorizar, para decorar".

Esta incoerência torna-se mais explícita quando se confrontam as percepções das alunas com as dos pais:

Aluna A - não sei se estudo muito ... Estudo todos os dias. Mas não tenho bem ideia de quantas horas.

Pai da Aluna A- Eu não sei, mas é bastante aplicada, não é preciso mandar estudar ... Ela sabe o que tem de fazer. Ás vezes pode estar a estudar até ás 2 ou 3 da manhã.

Aluna B - Não, eu não acho que estude muito, aliás, este ano, até, acho que podia ter estudado mais...

Irmã da Aluna B - "A [nome da aluna] é uma pessoa que gosta muito de fazer revisões antes dos testes e aplica-se muito nisso.

Mãe da Aluna B - Ela é uma criança que se tiver um teste não sai, nem comigo nem com ninguém. E depois é uma criança que é capaz de estar até à 1 hora da noite... E depois de manhã é assim 'Mãezinha eu estudei, mas às $6 \mathrm{~h} 30$ acorde-me'... Ela teve um teste que desceu um bocadinho, olhe que ela emagreceu muito....

De comum ao discurso construído pelas entrevistadas é o fato de, na realidade, todas acabarem por revelar um grande investimento no estudo que aparece, contudo, de uma forma mascarada ou dissimulada. 
Estas contradições podem significar, por um lado, que admitir imediatamente que se é inteligente poderia ser considerado "politicamente incorreto", mas, por outro lado, demonstra alguma dificuldade em tomar uma posição face a estes dois discursos que circulam tanto nos corredores onde se produz o conhecimento, como naqueles em que ele é ministrado a um nível de escolaridade básica. Note-se, contudo, uma total ausência nos discursos das entrevistadas de uma atribuição dos seus resultados escolares à sorte, $\mathrm{O}$ que torna mais explícita a importância dada à inteligência e ao esforço. Não é também de deixar de fora a hipótese de outra explicação muito difundida nos meios acadêmicos: que quem é muito inteligente precisa de se esforçar menos do que quem possui esse atributo em menor grau (Bandura, 1991; Weiner, 1991). Mas a contradição e ambigüidade face ao discurso da inteligência e do esforço pode ter outra justificativa. Segundo Walkerdine (1988, 1998), as classificações escolares elevadas, quer das moças, quer dos alunos ou alunas das classes sociais baixas, são explicadas através do esforço ou grande capacidade de estudo, por oposição aos rapazes e alunos e alunas das classes elevadas que são atribuídas à inteligência. $\mathrm{O}$ fato das três alunas entrevistadas associarem a categoria sexo feminino com a posição de classe desfavorecida pode explicar este constante "saltitar" entre discurso da inteligência e o do esforço.

Sem que seja frontalmente assumida como tal, a capacidade intelectual é relegada ao segundo plano, em comparação com o esforço, através de sofisticados mecanismos em que: a inteligência é confundida com o esforço; a inteligência é desvalorizada porque inteligentes somos todos (Aluna A); se desconhece o significado de inteligente; se ignora se é ou não possuidora dessa "qualidade". Ao mesmo tempo, está ausente destes discursos qualquer referência a uma conjugação da inteligência com o esforço, bem como à idéia de que a inteligência pode ser treinada precisamente através do estudo.

Assim, o efeito deste tipo de construções discursivas ambíguas e contraditórias, sobre o esforço e a inteligência poderia ser uma maneira destas alunas se protegerem de uma baixa de auto-estima (e conseqüente diminuição de percepções de auto-eficácia) associada a uma incerteza face à sua própria inteligência sobre a qual, como já foi visto, manifestam igualmente muitas dúvidas devido às atribuições causais de que geralmente são alvo as moças, como categoria social, e os alunos e alunas da classe trabalhadora. Por outro lado, o peso do modelo familiar, assente no esforço, poderá ter uma influência considerável no modo como as entrevistadas enunciam a questão acadêmica e explicam o seu rendimento escolar.

\section{Discurso sobre os professores: $O$ discurso da legitimidade}

O "discurso da legitimidade" diz respeito aos discursos proferidos tanto pelas alunas como pela família sobre a relação que têm tido com os professores.

Segundo Bourdieu e Passeron (1970) para que a autoridade pedagógica se torne legítima têm de ocorrer simultaneamente duas condições: a primeira é de que o emissor pedagógico (Ex.: o professor) seja considerado digno de transmitir o que transmite; a segunda condição é de que o receptor pedagógico (no caso da escola, o aluno ou aluna) esteja disposto a reconhecer a legitimidade e a autoridade do emissor pedagógico e, assim, receber e interiorizar a sua mensagem. Parece ser o que acontece nos discursos proferidos, quer pelas alunas quer pelos seus familiares.

Em termos concretos, o discurso sobre os professores demonstra existir uma relação predominantemente positiva entre estas alunas e os professores/professoras, que se caracteriza por uma imagem globalmente favorável das alunas face aos professores e por comportamentos de apoio/ajuda, por parte dos mesmos:

Aluna A - Professores? ... Ajudou-me... Mas acho que todos, em geral, se preocupam....-Sim, alguns.

Apesar de existir uma certa contradição entre uma primeira afirmação Mas acho que todos, em geral, se preocupam e a resposta seguinte $\mathrm{Sim}$ alguns, pode-se depreender que apesar de nem todos se preocuparem alguns manifestam efetivamente esse comportamento.

Aluna B.-. Eram excelentes. Eram umas professoras excelentes. Nisso por acaso tive sorte, acho que sim.... Sim incentivavam-me bastante e ajudavam muito.

A mãe desta aluna, mesmo sem ter sido questionada sobre esse assunto, acentua a idéia expressa pela filha:

Mãe da Aluna B- Graças a Deus, a nível de professores, foram sempre muito atenciosos, que não é para a gabar, com a minha (nome da aluna), muito compreensivos.

$\mathrm{Na}$ análise do discurso o dito torna-se tão importante como ou não dito (Wood \& Kroeger, 2000). No caso deste estudo, e no que se refere aos professores, o que está ausente é qualquer discurso de resistência, mesmo relativamente à relação dos professores com outros alunos. Mesmo quando se admite que um ou outro professor tinham uma relação menos boa, isso é encarado com naturalidade, pois existiram outros/as com os/as quais a relação era positiva. A autoridade científica e pedagógica não é questionada, mas legitimada. 
Os professores dão-lhes sugestões conducentes a um comportamento mais adequado ao sucesso escolar como referem as duas alunas seguintes:

Aluna B - Aliás não sou nada participativa e é o único ponto em que me estão sempre a chamar a atenção, mesmo nas reuniões dizem à minha mãe. Ainda este ano tive uma professora que me avisou para eu para no ano não continuar assim, porque só me estou a prejudicar

Aluna A - querem é que eu tenha boas notas no ano seguinte, acho que é isso!

O principal efeito desta produção discursiva parece ser, assim, o de criar uma relação de reciprocidade positiva entre professores, pais e alunas. Para as alunas e encarregados de educação ele é representado pelo apoio, a transmissão de expectativas positivas e todo o incentivo de que precisam para serem bem sucedidas. Para os professores traduz-se no reconhecimento da sua legitimidade e da escola (Bourdieu \& Passeron, 1970). Em última análise, o efeito deste discurso é permitir às alunas adquirir um capital cultural (Bourdieu, 1986, 1989), que lhes permita alcançar uma posição social distinta da sua origem social.

\section{Discussão}

Ao longo da análise das entrevistas verificou-se que os familiares destas alunas e as próprias alunas recorrem aos discursos oficiais do sistema educativo, que são usados essencialmente pelos professores e pela literatura especializada da psicologia como fatores que promovem a motivação para a realização.

Diversos estudos têm demonstrado que dos vários grupos sociais que freqüentam a escola, este tipo de discurso (que passa por presença nas reuniões da escola, encorajamento ou ajuda nos trabalhos de casa, expectativas elevadas face à realização escolar, criação de condições ambientais para essa mesma realização, tais como ter computadores, livros, fraca participação nas tarefas domésticas, etc) é usado preferencialmente pelas famílias da classe média (Allatt, 1993).

A prática discursiva das famílias aqui entrevistadas leva a crer que, e utilizando a linguagem de Bourdieu e Passeron (1970), estes pais conseguiram criar um habitus primário familiar muito próximo do babitus secundário escolar minimizando, assim, a distância entre os dois e facilitando o "trabalho pedagógico secundário" que neste caso é o trabalho escolar. É precisamente na classe média que esta situação costuma ocorrer facilitando aos alunos desta cultura dominante o acesso à compreensão da cultura escolar e, assim, ao sucesso acadêmico (Ayste, Flecha, Lopez-Palma \&Lleras, 1994; Bernstein, 1977; Bourdieu \& Passeron, 1970).

Que meios, ou estratégias, permitem às famílias deste estudo ter acesso a estes habitus da classe dominante e às práticas discursivas que lhes são inerentes? Um desses meios poderá estar relacionado com a própria motivação das mães para o estudo e com a sua própria percepção da mobilidade social que pode ser alcançada através da escola (Bilton \& cols., 1996). Como refere Skeggs (1997), as mães das classes trabalhadoras manifestam uma enorme preocupação em que as filhas melhorem as suas condições de vida. E esta melhoria passa, precisamente, pela educação, pois esta é um meio de transformar o capital cultural em capital econômico.

Esta "(in)consciência" fez com que as mães das alunas entrevistadas acompanhassem mais de perto toda a vida escolar das filhas e que se deslocassem à escola e falassem mais com os professores do que é comum nas famílias da sua posição de classe. Por outro lado esta presença freqüente na escola, ao longo dos últimos 10 anos, poderá ter-lhes permitido a interiorização do discurso dos professores sobre as condições promotoras de sucesso escolar, discurso este que por sua vez reproduziram nas alunas. Nesta ordem de idéias, o que estas famílias reproduziram nas alunas não foram as relações culturais e sociais da sua classe, mas as da classe dominante.

Por outro lado, se estes pais vão tão freqüentemente à escola (não para contestar, mas para reiterarem a sua confiança na mesma) é porque reconhecem autoridade e legitimidade pedagógica (tal como é entendida por Bourdieu \& Passeron, 1970) ao professor ou professora, o que lhes permite receber e interiorizar a sua mensagem com facilidade. Em vez do discurso de crítica à instituição escolar em geral ou a alguns aspectos particulares da mesma, estes familiares e alunas utilizam um discurso em que perpassa a idéia de que a escola é um local onde todos, seja qual for a sua condição de classe, gênero ou raça, têm a mesma igualdade de oportunidades e de resultados.

Tendo em conta que a escola avalia cada aluno segundo o grau em que ele domina a cultura dominante e que os alunos que herdaram o capital cultural valorizado pela escola são vistos como mais inteligentes e dotados (Ayste \& cols., 1994), poder-se-á pensar que estas alunas serão consideradas pelos professores e professoras como mais inteligentes que a maioria. Dito de outro modo, este tipo de percepções pode influenciar as expectativas dos professores e contribuir para melhores classificações escolares do que aquelas que seriam dadas a alunos com o mesmo rendimento, mas menos adaptados à cultura dominante.

O fato dos próprios pais assumirem para si a responsabilidade no sucesso das filhas é, também, uma forma 
de desculpabilizarem a escola da sua quota-parte de responsabilidade no insucesso dos outros. É, portanto, mais uma forma de evitarem comportamentos de resistência e de reconhecerem que a escola é um local de desigualdade em que muito poucos têm a possibilidade de "saltar a barreira".

Neste contexto de conformidade com a prática discursiva dominante poder-se-ia perguntar quais são os custos e os benefícios que esta prática implica?

A curto prazo o benefício desta prática poderá ser o de promover o sucesso escolar das alunas e, a longo prazo, uma mobilidade social ascendente através de mecanismos essencialmente individuais que passam, precisamente, pela escolarização prolongada. Estes são processos analisados e referidos, por exemplo, por Tajfel (1983) e que se baseiam na crença, à semelhança do "sonho americano", que é possível através de uma desidentificação com o seu grupo de pertença alcançar uma mobilidade individual. Mas serão estes benefícios reais?

Os custos desta prática de conformidade com o discurso dominante podem ser vários. Um deles consiste num enorme esforço econômico por parte do agregado familiar (horasextras, ausência de férias, etc.). Para as alunas o preço a pagar pode ser de outra ordem, tendo em conta os resultados das investigações realizadas, por exemplo, por Skeggs (1997) e por Frazer (1989). Destes estudos pode-se concluir que, tanto as mulheres da classe trabalhadora, que fazem tudo o que está aos seu alcance para se desidentificarem e dissimularem a sua condição de classe (Skeggs, 1997), como as moças evitam a todo o custo falar sobre o assunto, considerando a classe um assunto ambíguo, vago e embaraçoso (Frazer, 1989).

Numa lógica essencialmente social o discurso da regulação contribui para uma posição ambígua face à classe de origem (ainda que permita alcançar uma mobilidade individual ascendente). Esta ambigüidade gera, provavelmente, conflitos de identidade com os outros significativos. E se é verdade que a contradição de imagens que compomos acerca de nós é uma constante da identidade (Davis \& Harré, 1990; Weedon, 1987) será também de imaginar que existem "conjuntos" de imagens mais difíceis de gerir do que outros. Para as moças da classe trabalhadora, como refere Reay (1997), ter sucesso acadêmico significa recusar todo o sistema de significado de classe. Ao mesmo tempo ter sucesso é, ainda segundo a mesma autora, uma prova de meritocracia que serve para desvalorizar aqueles que fracassam.

As causas do insucesso dos alunos e alunas da classe trabalhadora têm sido alvo de muitos estudos e reflexões (Ex.: Bourdieu \& Passeron, 1970; Giroux, 1997; McLaren, 1986; Willis, 1977). Parece, no entanto, ser justo pensar que o caminho para o sucesso dos alunos e alunas da classe trabalhadora não pode ser feito à custa da sua identidade; não pode levar a que os atores em causa não saibam como se situar, nem o lugar que ocupam na sociedade. Como referem Mahoney e Zmroczek (1997, p.1), professoras universitárias e provenientes da classe trabalhadora:

Enquanto acreditarmos que era um insulto para outras pessoas da classe trabalhadora fingir que as nossas vidas eram iguais às deles, tendo em conta os privilégios que nos foram concedidos pela nossa profissão da classe média, nunca sentiremos que habitamos o mundo da universidade do mesmo modo que a maioria dos nossos colegas (incluindo outras feministas).

\section{Referências}

Allatt, P. (1993). Becoming privileged: The role of family processes. Em I. Bates \& G. Riseborough (Orgs.), Youth and inequality (pp. 139-159). Buckingham: Open University Press.

Ayste, A., Flecha, R., Lopez-Palma, F. \& Lleras, J. (1994). Planteamentos de la pedagogia critica: Comunicar e transformar: Barcelona: Gráo.

Bakhtin, M. M. (1984). Problems of Dostoevsky's poetics. Minneapolis: University of Minnesota Press. (Original publicado em 1929)

Bandura, A. (1986). Social foundations of thought and action: A social cognitive theory. Englewood Cfiffs, NJ: Prentice-Hall.

Bandura, A. (1991). Self- regulation of motivation through antecipatory and self reactive mechanisms. Em R. A. Dienstbier (Org.), Perspectives on motivation (pp. 69-164). Lincoln: University of Nebraska Press.

Barr, R. D. \& Parrett, W. H. (1995). Hope at last for at-risk students. London: Allyn and Bacon.

Bates, I. (1993). A job which is 'right' for me: Social class, gender and individualization. Em I. Bates \& G. Riseborough (Orgs.), Youth and inequality (pp. 14-31). Buckingham: Open University Press.

Bernstein, B. (1977). Class, codes and control: Theoretical studies towards a sociology of language (Vol. 1). London: Routledge \& Kegan Paul.

Bilton, T., Bonnett, K., Jones, P., Skinner, D., Stanworth, M. \& Webster, A. (1996). Introductory sociology. London: MacMillan.

Bourdieu, P. (1986). Distinction: A social critique of the judgement of taste. London: Routledge.

Bourdieu, P. (1989). Social space and symbolic power. Sociological Theory, 7, 1425.

Bourdieu, P. \& Passeron, J. C. (1970). La reproduction: Éléments pour une theorie du systeme d'enseignement. Paris: Les Editions de Minuit.

Davis, B. \& Harré, R. (1990). Positioning: The discursive production of selves. Journal for the Theory of Social Behaviour, 20, 43-63.

Deleuze, G. \& Guattari, F. (1987). A thousand plateaus: Capitalism and schizophrenia. Minneapolis: University of Minnesota.

Edwards, D. \& Potter, J. (1992). Discursive psychology. London: Sage.

Fee, D. (2000). Pathology and the postmodern. London: Sage.

Foucault, M. (1994). História da sexualidade I - A vontade de saber. Lisboa: Relógio D’ Água. (Original publicado em 1976)

Frazer, E. (1989). Feminist talk and talking about feminism: Teenage girl's discourses of gender. Oxford Review of Education, 15(3), 281-290.

Gergen, K. J. (1982). Toward transformation in social knowledge. London: Sage.

Gergen, K. J. (1985). The social constructionist movement in modern psychology. American Psychologist, 40, 266-275.

Gergen, K. J. (1994). Realities and relationships. Soundings in social construction. Cambridge: Harvard University Press.

Gergen, K. J. (2001). Psychological science in a postmodern context. The American Psychologist, 56, 803-813. 
Giroux, H. A. (1997). Pedagogy and the politics of hope: Theory, culture, and schooling. Oxford: Westview Press.

Goffman, E. (1993). A apresentação do eu na vida de todos os dias. Lisboa: Relógio D' Água. (Original publicado em 1959)

Harré, R. (1995). Discursive psychology. Em J. A. Smith, R. Harré \& L. Van Langenhove (Orgs.), Rethinking psychology (pp. 143-159). London: Sage.

Harré, R. \& Gillet, G. (1994). The discursive mind. London: Sage.

Iñiguez, L. \& Antaki, C. (1994).El analisis del discurso en psicologia social. Boletin de Psicologia, 44, 57-75.

Kvale, S. (1992). Psychology and post-modernism. London: Sage.

Llombart, M. (1993). Mujer, relaciones de género y discurso. Revista de Psicologia Social, 8(2),201-215.

Mahoney, P. \& Zmroczek, C. (1997). Why class matters. Em P. Mahoney \& C. Zmroczek (Orgs.), Class matters: Working class women's perspectives on social class (pp. 1-7). London: Taylor and Francis.

Manning, M. L. \& Baruth, L. G. (1995). Students at risk. London: Allyn and Bacon.

McLaren, P. (1986). Schooling as a ritual performance. London: Routledge \& Kegan Paul.

Nogueira, C. (2001). Um novo olhar sobre as relaçoes sociais de género: Feminismo e perspectivas críticas na psicologia social. Lisboa: Fundação Calouste Gulbenkian.

Parker, I. (1992). Discourse dynamics: Critical analysis for social and individual psychology. London: Routledge.

Parker, I. (1999). Varieties of discourse and analysis. Em I. Parker and the Bolton Discourse Network (Orgs.), Critical textwork: An introduction to varieties of discourse and analysis (pp. 1-13). Buckingham: Open University Press.

Perista, H. (1999). Os usos do tempo e o valor do trabalbo: Uma questão de género. Lisboa: CESIS.

Potter, J. (1996). Representing reality: Discourse, rhetoric and social construction. London: Sage.

Potter, J. \& Wetherell, M. (1987). Discourse and social psychology. London: Sage.

Rak, C. \& Patterson, L. (1996). Promoting resilience in at-risk children. Journal of Counseling and Development, 744, 368-373.

Reay, D. (1997). The double bind of working class feminist academic: The success of failure or the failure of success?. Em P. Mahoney \& C. Zmroczek (Orgs.), Class matters: Working class women's perspectives on social class (pp. 18-29). London: Taylor and Francis.
Roberts, K. (1993). Career trajectories and the mirage of increased social mobility. Em I. Bates \& G. Riseborough (Orgs.), Youth and inequality (pp. 229- 245). Buckingham: Open University Press.

Saavedra, L. (2001a). Sucesso/insucesso escolar: A importância do nível socio-económico e género. Psicologia, XV(1), 67-92.

Saavedra, L. (2001b). Vozes de sucesso, vozes (silenciadas) de fracasso: Género e classe social na escola. Dissertação de Doutorado não-publicada em Psicologia (Psicologia da Educação), Instituto de Educação e Psicologia, Universidade do Minho, Braga. Braga, Portugal.

Sagor, R. (1996). Building resiliency in students. Educational Leadership, 541, 38-43.

Schunk, D. H. (1990, abril). Socialization and the development of self regulated learning: The role of attributions. Trabalho apresentado no Annual Meeting of the American Educational Research Associations, Boston, MA.

Shotter, J. (1997). The social construction of our inner selves. Journal of Constructivist Psychology, 11(4), 7-24.

Skeggs, B. (1997). Formations of class \& gender. London: Sage.

Rogers, W. S. (1998, julho). Not just doing DA, but doing sometbing with it. Comunicação apresentada no seminário Discurse Practice: Qualitative Developments in Psychological Research, Bolton Institute,Blton, England.

Tajfel, H. (1983). Grupos humanos e categorias sociais. Lisboa: Livros Horizonte.

Walkerdine, V. (1988). The mastery of reason. London: Routledge.

Walkerdine, V. (1998). Counting girls out: Girls and mathematics. London: Falmer Press.

Weedon, C. (1987). Feminist practice and poststruturalist theory. New York: Basil Blackwell.

Weiner, B. (1991). On perceiving the other as responsible. Em R. A. Dienstbier (Org.), Perspectives on motivation (pp. 165- 198). Lincoln: University of Nebraska Press.

Willis, P. (1977). Learning to labour: Now working class kids get working class jobs. Aldershot: Gower.

Wood, L. A. \& Kroeger, R. O. (2000). Doing discourse analysis: Methods for studying action in talk and text. London: Sage.

Sobre a autora

Luísa Saavedra é Professora de Psicologia da Universidade do Minho (Braga,Portugal). É Doutora em Psicologia da Educação. 